\title{
Removing Substances from Blood by Affinity Chromatography
}

\author{
II. REMOVING BILIRUBIN FROM THE BLOOD \\ OF JAUNDICED RATS BY HEMOPERFUSION \\ OVER ALBUMIN-CONJUGATED AGAROSE BEADS
}

\author{
Bruce F. Scharschmidt, Paul H. Plotz, Paul D. Berk, \\ JeanNe G. Waggoner, and John Vergalla \\ From the Section on Diseases of the Liver, Digestive Diseases Branch, and the \\ Arthritis and Rheumatism Branch, National Institute of Arthritis, Metabolism \\ and Digestive Diseases, National Institutes of Health, \\ Bethesda, Maryland 20014
}

A в S TR ACT In vitro studies indicate that bilirubin and other albumin-bound substances can be efficiently removed from plasma by filtration over albumin-conjugated agarose beads. The effectiveness of this technique in vivo was investigated in rats by using a closed extracorporeal hemoperfusion system. Five Gunn rats whose endogenous bilirubin pool had been labeled with $\left[{ }^{3} \mathrm{H}\right]$ bilirubin and five Sprague Dawley rats with surgically created biliary obstruction were chosen as models of unconjugated and conjugated hyperbilirubinemia. Indocyanine green was injected into rats and its removal also studied. In the Gunn rats, $98 \%$ of the bilirubin was removed from plasma during the initial pass over the column as determined isotopically and chemically. Plasma bilirubin levels fell more than $70 \%$ from $8.2 \pm 1.6 \mathrm{mg} /$ $100 \mathrm{ml}$ (mean \pm SD) to $2.6 \pm 0.5 \mathrm{mg} / 100 \mathrm{ml}$ during a 1-h hemoperfusion. An average of $1,061 \mu \mathrm{g}$ of bilirubin

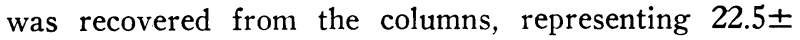
$4.2 \%$ of the total exchangeable bilirubin pool and $96 \pm$ $36.4 \%$ of the plasma pool. Results were similar in the rats with biliary obstruction and in those given indocyanine green. Normal Sprague Dawley rats experience minimal changes in formed blood elements, electrolytes, and proteins as the result of hemoperfusion. When the total volume of the column did not exceed $51 \%$ of the estimated blood volume of the animal, the survival rate was $100 \%$ in 20 studies, and the procedure was without observable ill effect. Extrapolation of both in vitro and in vivo data to man suggests that extracorporeal hemo-

Received for publication 9 August 1973 and in revised form 22 October 1973. perfusion over albumin-agarose columns may be a practical means of assisting hepatic excretory function.

\section{INTRODUCTION}

The accompanying paper describes the efficient removal of bilirubin $(\mathrm{BR})^{1}$ and other protein-bound substances from plasma and whole blood in vitro by filtration over agarose beads coupled to human serum albumin (HSA) (1). The purpose of the studies reported here was to evaluate the effectiveness of these beads in removing $\mathrm{BR}$ from the circulation in vivo when a simple extracorporeal hemoperfusion system was used. Congenitally jaundiced Gunn rats which lack glucuronyl transferase and rats with surgically created biliary obstruction were chosen as models of unconjugated and conjugated hyperbilirubinemia, respectively. Indocyanine green (ICG), another tightly albumin-bound substance, was injected into rats and its removal also studied. In addition, the effect of hemoperfusion on formed blood elements and plasma electrolytes was examined.

\section{METHODS}

Columns. In most of the experiments, Pharmacia K9/30 columns (Pharmacia Fine Chemicals, Inc., Piscataway, N. J.) were used. Some of these columns were modified by cutting and rethreading the plastic barrel to decrease the column volume and still allow use of the original ends. The bed supports and nylon mesh supplied with the column

${ }^{1}$ Abbreviations used in this paper: $\mathrm{BR}$, bilirubin; $\{\mathrm{BR}\}$, bilirubin concentration; $\mathrm{C}_{\mathbf{B R}}$, bilirubin clearance; $\mathrm{HSA}$, human serum albumin; ICG, indocyanine green. 
were replaced at both the top and bottom ends by plain or gold-plated (Alexandria Metal Finishers Inc., Alexandria, Va.) stainless steel cloth (200 mesh). Disposable polypropylene columns (Chromaflex, Kontes Glass Co., Vineland, N. J.) with nylon cloth ends (400 mesh) and Pharmacia K16 glass barreled columns treated with silicone (Dow Corning \#360 medical fluid, Dow Corning Corp., Midland, Mich.) were also used.

Agarose-albumin conjugates. Sepharose 6B (Pharmacia Fine Chemicals, Inc.) or Biogel A5m, 100-200 mesh (BioRad Laboratories, Richmond, Calif.) was coupled to HSA by methods described in the previous paper (1). The agarose-HSA conjugates contained $30-50 \mathrm{mg}$ HSA per gram wet wt of gel.

Packing was accomplished by pouring a slurry of agaroseHSA into a column containing a small amount of $0.14 \mathrm{M}$ sodium chloride and regulating the outflow at $1 \mathrm{~cm}^{3} / \mathrm{min}$ with an LKB Series 12,000 peristaltic pump (LKB Industries, Bromma, Sweden). When the column was fully packed and the upper retaining mesh put in place, air was expelled from the upper end by gently tapping the column while $0.14 \mathrm{M}$ sodium chloride was pumped into the lower end.

Extracorporeal hemoperfusion technique. The rat to be hemoperfused was anesthetized with a $50 \mathrm{mg}$ per $\mathrm{kg}$ intraperitoneal injection of pentobarbital (Abbott Laboratories, Chicago, III.) and an artery and vein cannulated with $\mathrm{PE}$ 50 tubing (Clay-Adams, Inc., Parsippany, N. J.). Although the right carotid artery and jugular vein were used in most instances, the femoral vessels were also used in animals undergoing multiple studies. The arterial cannula was connected to a modified Teflon stopcock which served as an inflow sampling site (2). This, in turn, was connected to the top end of the column containing the gel. Interposed between the bottom end of the column and the venous cannula were an LKB peristaltic pump which regulated the flow of blood in the circuit and a second (outflow) sampling site. The complete extracorporeal hemoperfusion circuit is shown in Fig. 1.

The extracorporeal circuit was primed with warmed heparinized saline $\left(2 \mathrm{U} / \mathrm{cm}^{3}\right)$, and the rat given $500 \mathrm{U} / \mathrm{kg}$ body wt of heparin intravenously. The arterial and venous cannulae were then connected and the pump started. Blood flow through the extracorporeal circuit was generally maintained at $1 \mathrm{~cm}^{3}$ per min. During the study, the rat's body temperature was monitored by a rectal thermometer and maintained at $36-37^{\circ} \mathrm{C}$ with an infrared lamp. Control blood samples for determination of plasma bilirubin concentration $(\{B R\})$ were obtained from the inflow sampling site at the beginning of the study. After a quantity of blood equivalent to the total volume of the column had passed through the circuit, a second sample was taken from the outflow sampling site. When compared with the control values, this sample allowed calculation of the percentage of $\mathrm{BR}$ removed by the gel during the initial pass. Perfusion was generally continued for $1 \mathrm{~h}$, and a blood sample was taken from the outflow sampling site just before termination of the study. At the completion of hemoperfusion, the blood remaining in the circuit was returned to the rat by flushing a single column volume of warmed, heparinized saline through the system. A final sample of rat blood was then taken from the arterial line for determination of plasma $\{B R\}$. Comparison of these last two samples indicated whether the gel had equilibrated with the plasma or was still removing $B R$ at the end of the study. The samples obtained from the rat before and after hemoperfusion indicated the overall

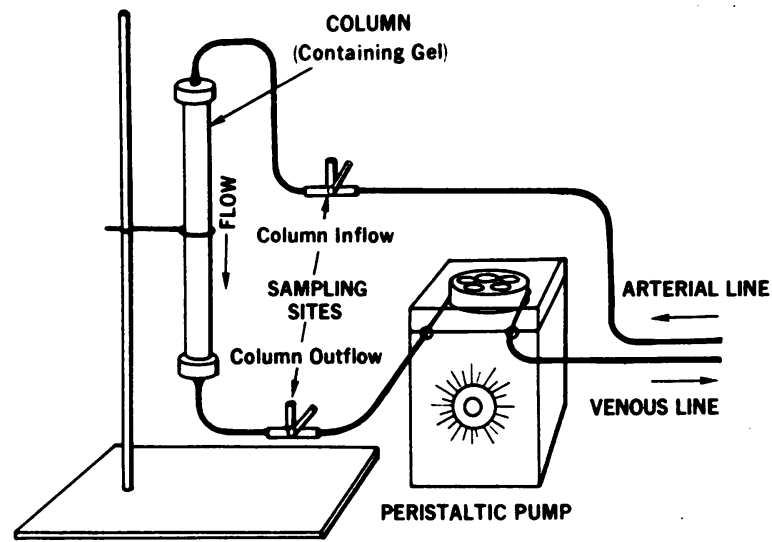

FIGURE 1 Extracorporeal hemoperfusion circuit.

efiectiveness of the procedure in lowering the plasma $\{B R\}$ in vivo.

At the completion of perfusion, the arterial and venous cannulae were removed and the rat allowed to awaken. The column was washed with two column volumes of phosphate-buffered saline $(0.14 \mathrm{M}$ sodium chloride- $0.01 \mathrm{M}$ sodium phosphate, $\mathrm{pH} 7.2$ ) and then with one column volume of $1.0 \mathrm{M}$ sodium chloride in the reverse direction. Elution with $50 \%$ ( $\mathrm{vol} / \mathrm{vol}$ ) ethanol in water was then performed as described (1), and the ethanol eluate assayed for BR and radioactivity.

Bilirubin measurements. The $\{\mathrm{BR}\}$ in rat plasma was determined on $20-\mu 1$ samples by using a micromodification of the method of Weber and Schalm (3). In the Gunn rat studies, the total $\{B R\}$ in the ethanol eluate obtained from the columns was determined by three different methods. (a) The van den Bergh reaction was used as described in the in vitro studies (1). (b) An aliquot of the ethanol eluate was diluted $1: 2$ in $4 \%$ HSA and the optical density at $454 \mathrm{~nm}$ measured. The $\{B R\}$ was then determined by comparing this value with standard curves obtained from known concentrations of $\mathrm{BR}$ dissolved directly in a $2 \%$ HSA-25\% ethanol solution. (c) A 1:5 dilution of the eluate in $5 \%$ HSA was subjected to the partition method of Weber and Schalm (3). With this dilution of the eluate, only one part in 96 of the total partition mixture was ethanol, and virtually all $(96 \pm 5.6 \%$, mean $\pm S D)$ of the unconjugated $\mathrm{BR}$ partitioned into the lower, nonpolar layer. Values obtained by these three methods agreed within an average of $\pm 4.6 \%$ of the mean and were averaged in the final results.

The total $\{B R\}$ in the ethanol eluates obtained from the rats with biliary obstruction was measured by the van den Bergh reaction, and the percentage of this total representing conjugated BR was determined by the WeberSchalm partition.

Indocyanine green measurements. The ICG concentration was determined in rat plasma by comparing the optical density at $805 \mathrm{~nm}$ with standard curves in rat plasma. The 50\% ethanol eluates were diluted $1: 2$ in $4 \%$ HSA and the optical density compared with standard curves of ICG dissolved in $2 \%$ HSA-25\% ethanol.

Animal preparation. A total of five studies was performed on four homozygous, jaundiced Gunn rats obtained from the Animal Resources Branch of the National In- 


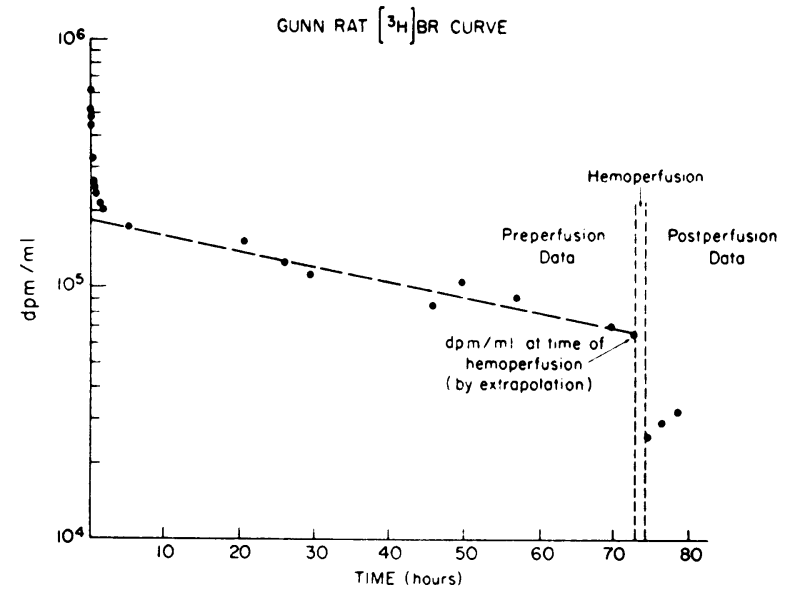

Figure 2 [ $\left.{ }^{3} \mathrm{H}\right] \mathrm{BR}$ disappearance curve in a jaundiced Gunn rat. The ordinate represents plasma radioactivity present in the lower, nonpolar layer of the Weber Schalm partition. The vertical dashed lines separate data obtained before and after the 1-h hemoperfusion.

stitutes of Health. Anesthetized Gunn rats were given an average of $6.6 \pm 0.6 \mu \mathrm{Ci}(54 \pm 5 \mu \mathrm{g})$ of $\left[{ }^{8} \mathrm{H}\right] \mathrm{BR}$, prepared in bile fistula dogs as previously described (4). By using a special sampling apparatus (2), arterial samples were obtained every $30 \mathrm{~s}$ for the first $3 \mathrm{~min}$ and at longer intervals thereafter. At $75 \mathrm{~min}$, the cannulae were removed and the animals allowed to awaken. Subsequent blood samples before extracorporeal hemoperfusion were obtained from a lateral tail vein over the next $72 \mathrm{~h}$ after which the animals were hemoperfused as described above. All plasma samples were subjected to a micromodification of the Weber-Schalm partition and the radioactivity extracted into the lower layer was used for calculation of the plasma isotope disappearance curve. The procedure is analogous to that previously described (5). A typical $\left[{ }^{3} \mathrm{H}\right] \mathrm{BR}$ disappearance curve in a jaundiced Gunn rat is shown in Fig. 2. Plasma BR pool and total miscible BR pool were calculated from the radiobilirubin disappearance curves and the plasma $\{B R\}$ as indicated below.

Radioactivity present in the injected material, the ethanol eluate from the perfused column, and the lower layer of the Weber-Schalm extraction of plasma samples were determined by standard liquid scintillation counting methods in Aquasol (New England Nuclear, Boston, Mass.), with internal standardization for quench correction. Multiple aliquots of the ethanol eluate were counted, and at least 5,000 counts were accumulated on all samples and background in order to insure that the error in the net count rate did not exceed $3 \%$.

To prepare the biliary obstruction rats, five normal Sprague Dawley rats were anesthetized and their bile ducts ligated through a small laparotomy incision. The plasma $\{B R\}$ generally plateaued in $3-5$ days and the animals were hemoperfused 1-10 days thereafter.

In preparation for the ICG studies, two Sprague Dawley rats were anesthetized and their bile ducts ligated. They were given $35 \mathrm{mg} / \mathrm{kg}$ ICG (Hynson, Westcott \& Dunning, Inc., Baltimore, Md.) intravenously and frequent arterial samples were obtained until a relatively stable plasma ICG concentration was reached. The animal was then hemoperfused.
Laboratory determinations. Blood electrolytes and calcium concentration and complete blood counts including platelet counts and leukocyte differential counts were performed on coded samples (Bionetics Medical Laboratories, Falls Church, Va.). Peripheral blood smears before, during, and after hemoperfusion were examined by the investigators. Plasma cortisol determinations were performed by radioimmunoassay in the laboratory of Dr. Lynn Loriaux at the National Institutes of Health. Total plasma thyroxine levels were determined by competitive protein binding in the National Institutes of Health clinical laboratories.

Other studies. An additional 23 normal Sprague Dawley rats were hemoperfused with columns of various volumes. Blood samples from the animals before and after perfusion in addition to samples of column effluent were examined for formed blood elements and blood chemistries.

Calculations. In the Gunn rat, the time required for distribution of the injected isotope between the various exchanging body pools $(\sim 90 \mathrm{~min})$ is relatively short when compared with the time required for ultimate disappearance of the isotope from the system (average biological half life $=39 \mathrm{~h}$ ). This permits analysis of the radiobilirubin disappearance data in terms of a unicompartmental model. Under this circumstance extrapolation of the final exponential to zero time $\left(\mathrm{T}_{0}\right)$ yields a reasonable estimate of the total volume of distribution of the injected isotope (TVDBR $)^{2}$ and hence the total size of the readily exchangeable bilirubin pool $(T B R P=T V D B R \times$ plasma $\{B R\}$. Extrapolation to $T_{0}$ of the portion of the curve defined by the initial 3-4 points, obtained during the first 1-2 min after injection of the isotope, yields an approximation of the plasma volume of distribution of the injected $\left[{ }^{3} \mathrm{H}\right] \mathrm{BR}$ (PVDBR) and hence, of the plasma bilirubin pool $(\mathrm{PBRP}=\mathrm{PVDBR} \times$ plasma $\{\mathrm{BR}\})$. The plasma $\left[{ }^{3} \mathrm{H}\right] \mathrm{BR}$ activity at the start of hemoperfusion $\left(\mathrm{dpm} / \mathrm{ml}_{\mathrm{H}}\right)$ was determined by extrapolating a least squares fit of the final exponential to the time of initiation of hemoperfusion. The plasma $\{B R\}$ in micrograms per milliliter $\left(\{B R\}_{p}\right)$ used in the calculation of the preperfusion pool sizes is the average of the values obtained $3 \mathrm{~h}$ before and at the onset of hemoperfusion. These two figures agreed quite closely. With these data, as well as the total radioactivity $\left(\mathrm{dpm}_{\mathrm{col}}\right)$ and micrograms of bilirubin $\left(\mathrm{BR}_{\mathrm{col}}\right)$ recovered from the column, the following calculations are possible.

1. Percentage of TBRP and PBRP removed during hemoperfusion as determined by column isotope recovery

$$
\begin{gathered}
\% \text { PBRP }=\frac{\mathrm{dpm}_{\mathrm{col}}}{\left(\mathrm{dpm} / \mathrm{ml}_{\mathrm{H}}\right) \times(\mathrm{PVDBR})_{\mathrm{ml}}} \times 100 \\
\% \mathrm{TBRP}=\frac{\mathrm{dpm}_{\mathrm{col}}}{\left(\mathrm{dpm} / \mathrm{ml}_{\mathrm{H}}\right) \times(\mathrm{TVDBR})_{\mathrm{ml}}} \times 100
\end{gathered}
$$

2. Percentage of TBRP and PBRP removed as determined by the number of micrograms of bilirubin recovered

Abbreviations used in these calculations and Table I: $B R_{c o l}$, bilirubin recovered from the column; $\{B R\}_{1 \mathrm{p}},\{B R\}$ in column effluent after first pass; $\{B R\}_{p}$, plasma bilirubin concentration at the beginning of hemoperfusion; dpm $\mathrm{dpo}_{\mathrm{c}}$, radioactivity recovered from the column; $\mathrm{dpm} / \mathrm{ml} \mathrm{H}_{\mathrm{H}}$, plasma $\left[{ }^{3} \mathrm{H}\right] \mathrm{BR}$ activity in the rat at the beginning of hemoperfusion; $\mathrm{dpm} / \mathrm{ml}_{\mathrm{ip}}$, radioactivity in column effluent present after first pass through circuit; PBRP, plasma bilirubin pool; PVDBR, plasma volume of distribution of $\left[{ }^{3} \mathrm{H}\right] \mathrm{BR}$; TBRP, total miscible bilirubin pool; TVDBR, total volume of distribution of $\left[{ }^{3} \mathrm{H}\right] \mathrm{BR}$. 
TABLE I

Removal of Bilirubin from Gunn Rats by Extracorporeal Hemoperfusion

\begin{tabular}{|c|c|c|c|c|c|c|c|}
\hline \multirow[b]{2}{*}{ Parameter* } & \multicolumn{5}{|c|}{ Individual Studies } & \multirow[b]{2}{*}{ Mean } & \multirow[b]{2}{*}{ SD } \\
\hline & 1 & 2 & 3 & $4 a$ & $4 b$ & & \\
\hline Weight $(g)$ & 417 & 400 & 427 & 360 & 415 & 404 & \\
\hline PVDBR/100 g $(\mathrm{ml})$ & 4.9 & 4.7 & 3.4 & 3.8 & 4.7 & 4.30 & 0.59 \\
\hline TVDBR $/ 100 \mathrm{~g}(\mathrm{ml})$ & 16.3 & 17.3 & 17.8 & 19.1 & 15.2 & 17.14 & 1.32 \\
\hline Biological $\mathrm{T} \frac{1}{2}$ of $\left[{ }^{3} \mathrm{H}\right] \mathrm{BR}$ & 51.3 & 52.5 & 34.0 & 31.5 & 26.4 & 39.14 & 10.71 \\
\hline \multicolumn{8}{|l|}{$\mathrm{BR}$}$(\mathrm{mg} / 100 \mathrm{ml})$ \\
\hline Plasma, preperfusion & 8.2 & 9.5 & 10.3 & 7.6 & 5.6 & 8.24 & 1.62 \\
\hline Plasma, postperfusion & 2.6 & 2.5 & 3.5 & 2.1 & 2.4 & 2.62 & 0.47 \\
\hline Column outflow after 1 st pass & 0 & 0.5 & 0 & 0 & & 0.12 & 0.22 \\
\hline Column outflow at end of study & & & 3.5 & & 1.9 & & \\
\hline$\%$ BR removed $_{\text {ip }}{ }^{\prime}$ & 100 & 94.7 & 100 & 100 & & 98.7 & 2.6 \\
\hline$\%$ BR removed rip & 99.8 & 88.9 & 100 & 100 & 98.9 & 97.5 & 4.3 \\
\hline \multicolumn{8}{|l|}{ BR eluted from column } \\
\hline Total $(\mu g)$ & 850 & 1,279 & 1,325 & 1,185 & 667 & 1,061 & 258 \\
\hline Per g gel $(\mu g / g)$ & 68.0 & 102.3 & 106.0 & 94.8 & 53.4 & 84.9 & 20.6 \\
\hline \multicolumn{8}{|l|}{ BR specific activity } \\
\hline Rat plasma pre perfusion & 662 & 733 & 322 & 450 & 574 & 548 & 147 \\
\hline Column eluate & 705 & 893 & 535 & 495 & 586 & 643 & 143 \\
\hline \multicolumn{8}{|l|}{$\%$ Total body pool removed } \\
\hline TBRP (\%) & 16.2 & 23.6 & 28.1 & 25.2 & 19.3 & 22.5 & 4.2 \\
\hline $\operatorname{TBRP}^{\prime}(\%)$ & 15.2 & 19.4 & 16.9 & 22.9 & 18.9 & 18.7 & 2.6 \\
\hline \multicolumn{8}{|l|}{$\%$ Plasma pool removed } \\
\hline $\operatorname{PBRP}(\%)$ & 55.0 & 86.8 & 148.6 & 127.1 & 62.5 & 96.0 & 36.4 \\
\hline $\operatorname{PBRP}^{\prime}(\%)$ & 51.6 & 71.2 & 89.4 & 114.4 & 61.3 & 77.6 & 22.3 \\
\hline
\end{tabular}

* See Methods, footnote 2, for explanation of symbols.

from the column

$$
\begin{aligned}
& \% \mathrm{PBRP}^{\prime}=\frac{\left(\mathrm{BR}_{\mathrm{col}}\right) \mu \mathrm{g}}{(\mathrm{PBRP}) \mu \mathrm{g}} \times 100 \\
& \% \mathrm{TBRP}^{\prime}=\frac{\left(\mathrm{BR}_{\mathrm{col}}\right) \mu \mathrm{g}}{(\mathrm{TBRP}) \mu \mathrm{g}} \times 100
\end{aligned}
$$

3. Specific activity of $\left[{ }^{3} \mathrm{H}\right] B R$ recovered from the column

$$
\frac{\mathrm{dpm}_{\mathrm{col}}}{\left(\mathrm{BR}_{\mathrm{col}}\right) \mu \mathrm{g}}
$$

4. Specific activity of $\left[{ }^{3} \mathrm{H}\right] \mathrm{BR}$ in the rat at the time of hemoperfusion

$$
\frac{\mathrm{dpm} / \mathrm{ml}_{\mathrm{H}}}{\left(\{\mathrm{BR}\}_{\mathrm{p}}\right) \mu \mathrm{g} / \mathrm{ml}}
$$

In addition, the isotope data and chemical measurements of BR obtained from the column outflow site after a single column volume of blood had passed through the perfusion circuit $\left(\mathrm{dpm} / \mathrm{ml}_{1 \mathrm{p}},\{B R\}_{1 \mathrm{p}}\right)$ permit calculation of the percentage of $B R$ removed during the initial pass over the column ( $\%$ BR removed $\left.{ }_{i p}\right)$.

5. Percentage removed as determined by isotope data

$$
\% B R \text { removed }_{\mathrm{ip}}=\frac{\left(\mathrm{dpm} / \mathrm{ml}_{\mathrm{H}}\right)-\left(\mathrm{dpm} / \mathrm{ml}_{\mathrm{ip}}\right)}{\left(\mathrm{dpm} / \mathrm{ml} l_{\mathrm{H}}\right)} \times 100
$$

6. Percentage removed as determined by chemical measurements

$$
\% B R \text { removed }_{i p}{ }^{\prime}=\frac{\left(\{\mathrm{BR}\}_{\mathrm{p}}\right)-\left(\{\mathrm{BR}\}_{\mathrm{ip}}\right) \mu \mathrm{g} / \mathrm{ml}}{\left(\{\mathrm{BR}\}_{\mathrm{p}}\right) \mu \mathrm{g} / \mathrm{ml}} \times 100
$$

\section{RESULTS}

Studies of Gunn rats. Five extracorporeal hemoperfusions were performed on four Gunn rats, and results of these studies are summarized in Table I. Columns $4 a$ and $4 b$ represent replicate studies on the same animal.

In only one experiment was any BR detectable in the column effluent by direct chemical measurement after a single pass through the column, and in this study the $\{B R\}$ fell from $9.5 \mathrm{mg} / 100 \mathrm{ml}$ to $0.5 \mathrm{mg} / 100 \mathrm{ml}$. $\left[{ }^{3} \mathrm{H}\right] \mathrm{BR}$ data also indicate that virtually all $(97.5 \pm 4.3 \%)$ of the bilirubin was removed from this first column volume of blood during the initial pass through the circuit. During the hour of hemoperfusion, plasma $\{B R\}$ in the rats fell more than $70 \%$ from $8.24 \pm 1.62 \mathrm{mg} / 100 \mathrm{ml}$ to $2.62 \pm$ $0.47 \mathrm{mg} / 100 \mathrm{ml}$. By chemical measurement, an average of $1,061 \mu \mathrm{g}$ of BR was recovered from the ethanol column 


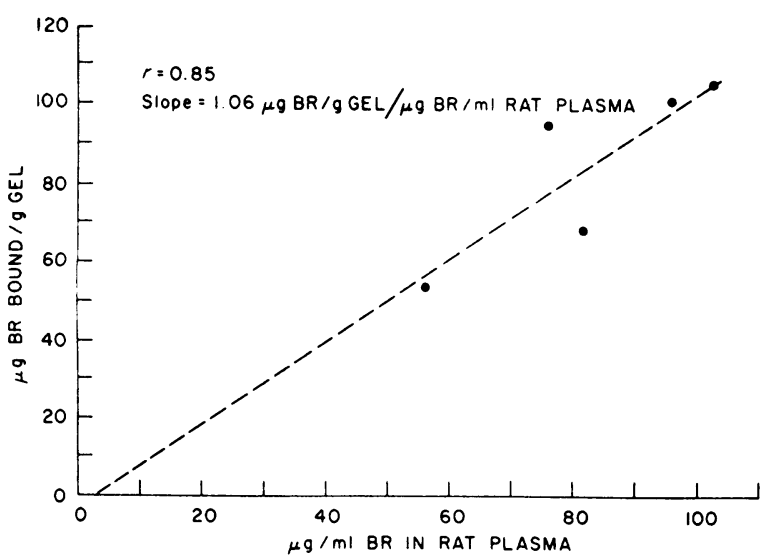

Figure 3 Relationship between the amount of unconjugated $\mathrm{BR}$ bound to the column expressed as $\mu \mathrm{g} / \mathrm{g}$ gel hemoperfusion (ordinate) and the $\{B R\}$ in the rat before hemoperfusion (abscissa).

eluates. This represents $77.6 \pm 22.3 \%$ of the initial preperfusion plasma bilirubin pool and $18.7 \pm 2.6 \%$ of the total body pool (\% $\mathrm{PBRP}^{\prime}$ and $\% \mathrm{TBRP}^{\prime}$ ). Analogous calculations based on measurements of radioactivity recovered from the column (\%PBRP, \% TBRP) show that $96.0 \pm 36.4 \%$ of the plasma bilirubin pool and $22.5 \pm 4.2 \%$ of the total miscible pool were removed. The fact that
\{BR\} did not drop to zero in those studies in which a quantity of BR equal to the entire PBRP was removed probably indicates mobilization of extravascular pools.

The specific activity of the $\mathrm{BR}$ recovered from the $50 \%$ ethanol eluates agreed quite closely in four of the five studies with the calculated specific activity of the $\mathrm{BR}$ in the rat before hemoperfusion. There was generally a several hour delay between the end of the perfusion and the chemical measurement of the BR in the ethanol eluate. Bilirubin is a highly light-sensitive compound and some photodegradation during this period may explain the slightly higher specific activity of BR recovered from the column when compared with that in the rat. In study 3 (Table I), technical problems with column elution resulted in a significant underestimate of the $\mathrm{BR}$ recovered from the column, as measured chemically. This may explain the greater discrepancy in specific activities observed in this particular study, as well as the fact that $\% \mathrm{TBRP}^{\prime}$ and $\% \mathrm{PBRP}^{\prime}$ determined chemically did not agree with corresponding values determined isotopically (Table I).

A $12.5-\mathrm{cm}^{3}$ column was used in all Gunn rat studies. The column appeared to have equilibrated with plasma at the end of each 60 -min perfusion. This conclusion was based on two observations. First, the column was uniformly yellow-orange from top to bottom. Second, the

TABLE II

Remoial of Bilirubin from Biliary Obstruction Rats by Extracorporeal Hemoperfusion

\begin{tabular}{|c|c|c|c|c|c|c|c|c|c|}
\hline \multirow[b]{2}{*}{ Parameter } & \multicolumn{7}{|c|}{ Individual studies } & \multirow[b]{2}{*}{ Mean } & \multirow[b]{2}{*}{ SD } \\
\hline & 1 & $2 a$ & $2 b$ & $3 a$ & $3 b$ & 4 & 5 & & \\
\hline Weight $(g)$ & 560 & 655 & & 665 & & 750 & 545 & 635 & \\
\hline Duration of study $(\mathrm{min})$ & 60 & 45 & 45 & 60 & 60 & 60 & 60 & 55.7 & \\
\hline Quantity of gel $(g)$ & 12.5 & 18 & 20 & 18 & 21.5 & 21 & 18 & 18.4 & \\
\hline \multicolumn{10}{|l|}{$B R$} rat, pre \\
\hline Total $(\mathrm{mg} / 100 \mathrm{ml})$ & 6.3 & 8.9 & 7.4 & 8.1 & 6.3 & 6.7 & 8.6 & 7.47 & 1.0 \\
\hline Conjugated $(\%$ of total $)$ & 86 & 92 & 93 & 91 & 92 & 100 & 88 & 91.7 & 4.1 \\
\hline \multicolumn{10}{|l|}{$B R$} rat, post \\
\hline Total $(\mathrm{mg} / 100 \mathrm{ml})$ & 5.0 & 5.1 & 4.7 & 6.3 & 3.9 & 4.1 & 5.1 & 4.88 & 0.73 \\
\hline Conjugated (\% of total) & 88 & 100 & 100 & 92 & 95 & 98 & 86 & 94.1 & 5.2 \\
\hline \multicolumn{10}{|c|}{$\mathrm{BR}$} column outflow $(\mathrm{mg} / 100 \mathrm{ml})$ \\
\hline After initial pass & 0.1 & 0.3 & 0.6 & 0 & 0.7 & 0 & 0 & 0.24 & 0.28 \\
\hline At end of study & 1.7 & 1.0 & 1.1 & 1.6 & 0.9 & 1.4 & 1.2 & 1.27 & 0.28 \\
\hline \multicolumn{10}{|l|}{ BR removed by gel $(\%)$} \\
\hline BR removed ip & 98.4 & 96.6 & 91.9 & 100 & 88.9 & 100 & 100 & 96.54 & 4.1 \\
\hline At end of study & 66.0 & 80.4 & 76.6 & 74.6 & 76.9 & 65.8 & 76.4 & 73.81 & 5.25 \\
\hline \multicolumn{10}{|l|}{ BR eluted from column } \\
\hline Total $(\mu g)$ & 1,160 & $930^{\circ}$ & 898 & 1,250 & 847 & 1,080 & 974 & 1,020 & 137 \\
\hline Conjugated (\% of total) & 88 & 94 & 90 & 91 & 87 & 100 & 87 & 91.0 & 4.3 \\
\hline
\end{tabular}


$\{B R\}$ in the column effluent just before the termination of hemoperfusion and the $\{B R\}$ in the rat after hemoperfusion agreed quite closely (Table I, studies 3 and $4 b$ ), suggesting that the column was no longer removing $\mathrm{BR}$ from the circulating rat blood at the end of the study. Together, these suggest that the amount of $B R$ bound to the gel should reflect, at least in part, the initial plasma $\{B R\}$ in the rat. When the quantity of bilirubin removed $(\mu \mathrm{g} / \mathrm{g}$ gel $)$ is plotted as a function of the initial plasma $\{B R\}(\mu \mathrm{g} / \mathrm{ml})$ (Fig. 3), a linear relationship is observed. Although the five Gunn rat studies represent a relatively narrow range of plasma $\mathrm{BR}$ concentrations, $(5.6-10.3 \mathrm{mg} / 100 \mathrm{ml})$, the slope of the regression line (1.06) and the correlation coefficient $(r=0.85)$ suggest that the column functions in vivo very much as it has in vitro (1). Furthermore, the data suggest that in these experiments the column capacity (up to $106 \mu \mathrm{g} / \mathrm{g}$ gel) was limited primarily by the initial $\{B R\}$ in the rat.

Biliary obstruction rats. Seven hemoperfusions performed on five rats with biliary obstruction are summarized in Table II. The data from two rats undergoing replicate studies are shown in columns $2 a$ and $b$ and $3 a$ and $b$. Unlike the Gunn rat, whose replicate studies were 3 wk apart, these were completed within several hours of each other.

Virtually all $(96.5 \%)$ of the predominantly conjugated $\mathrm{BR}$ in the obstructed rat studies was removed from the first column volume of blood passing through the gel. In addition, the percentage of total $\mathrm{BR}$ recovered from the column after hemoperfusion which was conjugated $(91.0 \%)$ was nearly identical to the percent conjugated $\mathrm{BR}$ present in the rat before hemoperfusion (91.7\%). In the rats with biliary obstruction and the Gunn rats the flow rate through the extracorporeal circuit $\left(1 \mathrm{~cm}^{8} /\right.$ $\mathrm{min}$ in all studies), the average $\mathrm{BR}$ concentration before hemoperfusion ( 7.47 and $8.24 \mathrm{mg} / 100 \mathrm{ml}$ ) and therefore the total BR load presented to the column, the total time of hemoperfusion ( 55.7 and $60 \mathrm{~min}$ ), and the total amount of BR removed from the column $(1,020$ and $1,061 \mu \mathrm{g}$ ) were very similar. It thus appears that the albumin-agarose beads bound conjugated $B R$ just as effectively as unconjugated.

The overall fall in $\{B R\}$ in the rats with biliary obstruction after hemoperfusion (from 7.47 to $4.88 \mathrm{mg} / 100$ $\mathrm{ml}$ ) was less than that in the Gunn rats. However, because of the significantly larger size of the rats with biliary obstruction (635 vs. $404 \mathrm{~g}$ ), the total number of plasma volumes passed through the column was less and the plasma and total miscible BR pools were greater in this group than in the Gunn rats.

Inspection of the columns following hemoperfusion showed them to be much more yellow-orange at the top than at the bottom, suggesting that complete equilibbration with plasma had not yet occurred. This observation was confirmed by comparison of the average $\{B R\}$ in the rat after hemoperfusion $(4.88 \mathrm{mg} / 100 \mathrm{ml})$ and in the column effluent at the termination of hemoperfusion $(1.27 \mathrm{mg} / 100 \mathrm{ml})$ which indicates that, at the end of the study, the column was still removing nearly $75 \%$ of the BR presented to it. This contrasts with the nearly complete equilibration of $\mathrm{BR}$ between the rat plasma and gel which occurred in the Gunn rat studies and probably reflects the fact that bigger columns were used in the rats with biliary obstruction (mean 18.4 vs. $12.5 \mathrm{ml}$ ).

Column elution. In both the Gunn and biliary obstruction rat experiments, essentially all the BR as determined chemically and all the radioactivity recovered from the column was contained in the $50 \%$ ethanol eluate. No BR or radioactivity was eluted with either the phosphate buffered saline or $1.0 \mathrm{M}$ sodium chloride washes.

The 50\% ethanol solution eluted both conjugated and unconjugated $\mathrm{BR}$ in a sharp band and returned the gel to a translucent state. The gel following ethanol elution in the Gunn rat studies was indistinguishable from freshly prepared gel. After elution of the predominantly conjugated $\mathrm{BR}$ in the biliary obstruction studies, however, the gel appeared a faint green. Elution with up to $70 \%$ ethanol did not remove this green color.

Indocyanine green rats. ICG, like conjugated and unconjugated $\mathrm{BR}$, was nearly completely cleared (average $=97.3 \%$ ) from the first column volume of blood on its initial pass through the circuit, and an average of $1,016 \mu \mathrm{g}$ of ICG was recovered from the ethanol eluate. The plasma ICG concentration decreased markedly after hemoperfusion in both studies (from an average of $23.7 \mathrm{mg} / 100 \mathrm{ml}$ before hemoperfusion to 10.7 $\mathrm{mg} / 100 \mathrm{ml}$ after hemoperfusion), although approximately $10-15 \%$ of this decrease may be attributed to continued hepatic clearance, since the ICG concentration had not quite plateaued when hemoperfusion was begun.

As in the studies with BR, no ICG was eluted with either phosphate buffered saline or $1.0 \mathrm{M}$ sodium chloride. The $50 \%$ ethanol solution eluted the ICG in a sharp green band and restored the gel to its pre-perfusion translucent state.

Additional data. Samples taken from rats before and after hemoperfusion, as well as from the column effluent, were examined for formed blood elements. Table III includes data from two representative studies. The hematocrits generally remained unchanged or decreased slightly, probably as a result of surgical blood loss, heparinization, blood sampling, and hemodilution. Erythrocyte morphology was unchanged. Platelet counts in the intact animal generally showed a modest decrease during hemoperfusion, and samples taken directly from the column effluent varied from unchanged to markedly decreased. Total leukocyte counts in the intact animal 
TABLE III

Hematological Effects of Extracroporeal Hemoperfusion

\begin{tabular}{|c|c|c|c|c|c|c|c|}
\hline & \multirow[b]{2}{*}{ Hematocrit } & \multirow[b]{2}{*}{ Hemlglobin } & \multirow[b]{2}{*}{ Platelets } & \multirow[b]{2}{*}{ White cells } & \multicolumn{3}{|c|}{ Differentials } \\
\hline & & & & & Polys & Lymplis & Monos \\
\hline & $\%$ & $\mathrm{~g} / 100 \mathrm{~cm}^{3}$ & $\times 10^{3} / \mathrm{mm}^{3}$ & per $m m^{3}$ & & $\%$ & \\
\hline \multicolumn{8}{|l|}{ Study 21} \\
\hline Rat, pre & 48.5 & 16.1 & 312 & 6,400 & 36 & 64 & \\
\hline Column outflow (1st pass) & 41.5 & 14.4 & 15 & 2,100 & 9 & 89 & 2 \\
\hline Rat, post & 44 & 14.7 & 217 & 11,000 & 51 & 45 & 2 \\
\hline Rat, $2 \mathrm{~h}$ post & 42 & 14.2 & 317 & 17,300 & 82 & 18 & \\
\hline \multicolumn{8}{|l|}{ Study 24} \\
\hline Rat, pre & 38.5 & 14.2 & 538 & 13,800 & 34 & 59 & 7 \\
\hline Column outflow (1st pass) & 32.5 & 12.1 & 307 & 5,300 & 2 & 97 & 1 \\
\hline Rat, post & 38.5 & 14.2 & 459 & 12,200 & 51 & 45 & 2 \\
\hline
\end{tabular}

either remained unchanged or increased, with a relative increase in the number of young forms. Samples obtained directly from the column effluent generally showed a selective loss of granulocytes, and granulocytes were found in the spun sediment from saline washes. Inspection of the gel and column components suggested that much of the loss of granulocytes and platelets which did occur was caused by trapping in the nylon or stainless steel cloth used to retain the gel, and not by the gel itself.

Two studies revealed no significant changes in plasma electrolytes or protein electrophoresis, and calcium decreased slightly from 10.8 to $10.1 \mathrm{mg} / 100 \mathrm{ml}$ and from 9.8 to $9.2 \mathrm{mg} / 100 \mathrm{ml}$ on two occasions. In three studies, plasma cortisol concentration in the rat decreased from $17.85 \pm 0.57 \mu \mathrm{g} / 100 \mathrm{ml}$ before perfusion to $12.70 \pm$ $0.82 \mu \mathrm{g} / 100 \mathrm{ml}$ after perfusion. The cortisol concentration in the column effluent was $0.21 \pm 0.29 \mu \mathrm{g} / 100 \mathrm{ml}$ after a single column volume of blood had passed through the system and $17.21 \mu \mathrm{g} / 100 \mathrm{ml}$ at the end of hemoperfusion (single study). Similar results were found in a single study of plasma thyroxine, which decreased from 8.1 to $1.7 \mathrm{\mu g} / 100 \mathrm{ml}$ in the rat following hemoperfusion with no detectable thyroxine in the column effluent after a single pass. Thyroxine levels in the column effluent at the end of the study were not measured. Although these results might suggest that cortisol, like $\mathrm{BR}$, is tightly bound to the beads, they are also compatible with simple retardation of cortisol by the albumin-agarose beads, as found in vitro (1). The fact that the cortisol concentration in the column outflow at the end of the study exceeded the simultaneous concentration in the rats supports the latter interpretation.

Survival data. A total of 34 animals have undergone 37 hemoperfusions. Four studies have been excluded from survival calculations. One involved a rat with biliary obstruction who died $24 \mathrm{~h}$ after hemoperfusion and 14 days after creation of the biliary obstruction. 2 wk has been the approximate lifespan of several animals with biliary obstruction who were not hemoperfused. The two rats given ICG also died shortly after hemoperfusion, but two similar animals with biliary obstruction given the same dose of ICG but not hemoperfused also died. In the fourth study, the rat died of respiratory obstruction due to a mucous plug which was verified at autopsy.

In the remaining 33 hemoperfusions, 24 animals awoke shortly after completion of the study and remained well for at least a week before being sacrified. This is an overall survival rate of $73 \%$. The total length of hemoperfusion (up to $2 \mathrm{~h}$ ), estimated number of blood volumes passed over the column (up to 4), and the animal's weight (200-900 g) did not influence survival. However, it was noted retrospectively that in the 13 studies (five in Gunn rats, eight in Sprague-Dawley rats) in which the column volume exceeded $51 \%$ of the estimated blood volume of the animal (estimated blood volume $=6 \% \times$ body weight), only four animals lived (one Gunn rat, three Sprague-Dawley rats). No attempt was made to prime the extracorporeal circuit with blood, plasma, or other volume expanders. It is probable, therefore, that the animals in this group, when drained of more than half their blood volume and given only an equal volume of saline in return, died of circulatory failure. In the remaining 20 studies, in which the column volume was less than $50 \%$ of the estimated blood volume, all the animals lived and the procedure was without observable ill effects.

\section{DISCUSSION}

A safe and effective method for the removal of proteinbound drugs and toxic metabolites from the body would find application in a number of clinical situations includ- 
ing drug intoxication and hepatic failure. A relatively new approach to this problem involves the adsorption of these substances onto insoluble particles or surfaces.

In the earliest experiments, ion exchange resins were administered by mouth or employed in extracorporeal hemoperfusion systems $(6,7)$. Various resin types have successfully removed protein-bound substances such as bromosulfophthalein, chenodeoxycholate, and unconjugated $B R$ in vitro (8). Further evaluation of this technique in vivo (9) has shown that bromosulfophthalein can be cleared effectively from plasma, while chenodeoxycholate and conjugated $\mathrm{BR}$ are less efficiently removed. ICG was not removed to any significant degree by the resins tested. Resin polymers can also effectively adsorb ammonia (10-14) and a limited trial of resin hemoperfusion in three patients with hepatic coma did significantly lower blood ammonia although clinical improvement was minimal and short-lived (15). Resin hemoperfusion has also been applied to the treatment of drug intoxication, and its use in the treatment of glutethimide and phenobarbital poisoning has been encouraging $(16,17)$.

These synthetic adsorbents vary widely in their ability to bind test compounds, and have the disadvantage of nonspecific binding of a variety of other plasma components. Thus, significant hypokalemia $(12,18)$ and hypocalcemia (19) have resulted from perfusion over charged ion exchange resins, although this problem may be circumvented by using a mixture of resins equilibrated with different counter ions $(12,13)$. Thrombocytopenia and leukopenia $(9,16)$ have also been complications during in vivo studies.

Activated charcoal readily adsorbs water-soluble wastes such as creatinine, uric acid, and guanidine derivatives $(20,21)$. The problems of blood compatibility and particle emboli have been largely overcome by microencapsulation with nylon, methacrylate, or cellulose nitrate (22-24), and hemoperfusion over microencapsulated charcoal has been effective in the clinical management of the uremic syndrome (25). Drugs such as acetylsalicyclic acid, acetaminophen, barbiturates, and glutethimide, which show some protein binding, have also been removed from plasma in vitro $(26,27)$ and in vivo (28-32) by this technique.

Charcoal has been minimally effective, however, in removing $\mathrm{BR}$, which is tightly albumin bound $(20,33)$. In a single case, attempts to assist hepatic excretory function in a patient with hepatic coma by hemoperfusion over albumin-coated microencapsulated charcoal was encouraging, although no change in blood ammonia and only small changes in $\{B R\}$ were reported (34). It is possible that the albumin coating of these microcapsules removed $B R$ independently of the charcoal core.

The use of HSA-agarose conjugates has two potential advantages compared to synthetic resins and acti- vated charcoal. The first is the predictable and selective removal only of those substances for which albumin serves as a carrier molecule. Second, the HSA-agarose beads appear to produce no significant changes in formed blood elements. The experiments described here demonstrate the efficient removal of the tightly albumin-bound substances, conjugated and unconjugated $B R$, and ICG from anesthetized rats by hemoperfusion over these beads.

There is evidence to suggest that rat albumin may bind unconjugated BR less tightly than does HSA (35). However, since the albumin-agarose beads were as effective in removing unconjugated $\mathrm{BR}$ from human plasma in vitro (1) as rat plasma in vivo, it is unlikely that any species differences in albumin-binding affinities explains the effectiveness of these beads in this study.

It is possible to calculate the $\mathrm{BR}$ clearance $\left(\mathrm{C}_{B R}\right)$ achieved by the gel in these studies as follows:

$$
\mathrm{C}_{\mathrm{BR}}=(\text { flow rate }) \times(\% \mathrm{BR} \text { removed })
$$

where the percentage of $B R$ removed by the column is calculated as described above (Eqs. 5 and 6). Since the BR was essentially completely cleared from blood during the first pass over the column in all studies, $\mathrm{C}_{\mathbf{B R}}$ was approximately $1 \mathrm{~cm}^{3} / \mathrm{min}$ initially, and was limited only by the flow rate in the extracorporeal circuit. In the rats with biliary obstruction, where columns of greater bed volume were used, C $_{\mathbf{B} \text { R }}$ was still $\sim 0.75 \mathrm{~cm}^{3} /$ min at the termination of the study. These values compare favorably with preliminary results indicating that hepatic BR clearance in normal Sprague Dawley rats is $0.30 \pm 0.02 \mathrm{~cm}^{3} / \mathrm{min} / 100 \mathrm{~g}$ body weight (36).

Laboratory data obtained from the rats before and after hemoperfusion indicate that the intact rat experiences minimal or no changes in the basic blood chemistries measured, or in formed blood elements during hemoperfusion. When the column volume did not exceed $51 \%$ of the estimated blood volume, the survival rate was $100 \%$.

Although potential problems such as sterility, pyrogenicity, particle emboli, and hemodynamics must be resolved, it is nevertheless interesting to speculate on the clinical feasibility of this approach for assisting hepatic excretory function. A $70-\mathrm{kg}$ man with a normal red blood cell volume and lifespan produces $\sim 1,900$ $\mathrm{mg}$ of $\mathrm{BR} / \mathrm{wk}$. If it is assumed that $(a)$ he is totally unable to clear this endogenous $\mathrm{BR}$ load, $(b)$ his average plasma $\{B R\}$ before extracorporeal hemoperfusion is $10 \mathrm{mg} / 100 \mathrm{ml}$, and $(c)$ an extracorporeal flow of $100 \mathrm{~cm} / 3 \mathrm{~min}$ can be maintained (easily achieved with arterio-venous shunts currently in use), it would be possible to achieve an initial $C_{\mathbf{B R}}$ of $\sim 100 \mathrm{~cm}^{3} / \mathrm{min}$ $(10 \mathrm{mg} / \mathrm{min})$ over a fresh column. In comparison hepatic $C_{\text {BR }}$ in normal man is $47 \pm 10 \mathrm{~cm}^{3} / \mathrm{min}$ (5). At a clearance rate of $100 \mathrm{ml} / \mathrm{min}$, an entire week's production of 
$\mathrm{BR}$ could be removed in slightly over $3 \mathrm{~h}$. In practice, a longer period would certainly be required since $C_{B R}$ will decrease as the column approaches equilibration, and the rate of $\mathrm{BR}$ removal (milligrams per minute) will fall as the plasma concentration declines. Furthermore, columns would need to be changed so that one could be eluted and regenerated while another was in use. Even if this results in a quadrupling of the time required to completely remove a week's endogenous $\mathrm{BR}$ production, the total of $12 \mathrm{~h} / \mathrm{wk}$ compares favorably with that of standard hemodialysis programs for patients with renal failure. In more acute situations such as drug overdosage, hepatic coma, and neonatal jaundice, this approach may be more effective and perhaps less cumbersome and hazardous than exchange transfusion.

Extracorporeal hemoperfusion over agarose bound albumin gels may thus be a practical means of assisting hepatic excretory functions in selected situations. Furthermore, use of specific binding proteins other than albumin may allow application of the general principle to a variety of clinical problems.

\section{REFERENCES}

1. Plotz, P. H., P. D. Berk, B. F. Scharschmidt, J. K. Gordon, and J. Vergalla. 1974. Removing substances from blood by affinity chromatography. I. Removing bilirubin and other albumin-bound substances from plasma and blood with albumin-conjugated agarose beads. J. Clin. Invest. 53 : 778.

2. Scharschmidt, B., and P. D. Berk. 1973. A simple device to facilitate rapid blood sampling in small animals. Proc. Soc. Exp. Biol. Med. 143: 364.

3. Weber, A. P., and L. Schalm. 1962. Quantitative separation and determination of bilirubin and conjugated bilirubin in human serum. Clin. Chim. Acta. 7: 805 .

4. Howe, R. B., P. D. Berk, J. R. Bloomer, and N. I. Berlin. 1970. Preparation and properties of specifically labelled radiochemically stable ${ }^{3} \mathrm{H}$-bilirubin. J. Lab. Clin. Med. 75: 499.

5. Berk, P. D., R. B. Howe, J. R. Bloomer, and N. I. Berlin. 1969. Studies of bilirubin kinetics in normal adults. J. Clin. Invest. 48: 2176.

6. Dock, W. 1946. Sodium depletion as a therapeutic procedure: the value of ion-exchange resins in withdrawing sodium from the body. Trans. Assoc. Am. Physicians Phila. 59: 282.

7. Muirhead, E. E., and A. F. Reid. 1948. A resin artificial kidney. J. Lab. Clin. Med. 33: 841.

8. Willson, R. A., K. H. Webster, A. F., Hofmann, and W. H. J. Summerskill. 1972. Towards an artificial liver: in vitro removal of unbound and protein bound plasma compounds related to hepatic failure. Gastroenterology. 62: 1191.

9. Willson, R. A., A. F. Hofmann, and G. G. R. Kuster. 1974. Towards an artificial liver. II. Removal of cholephilic anions from dogs with biliary obstruction by hemoperfusion through charged and uncharged resins. Gastroenterology. 66: 95 .

10. Schechter, D. C., T. F. Nealon, Jr., and J. H. Gibbon, Jr. 1958. A simple extracorporeal device for reducing elevated blood ammonia levels. Surgery. 44: 892.

11. Ritchie, H. D., D. M. Davies, J. M. Godfrey, P. Fan,
R. G. S. Johns, and J. Perrin. 1962. Extracorporeal methods of reducing high blood ammonia levels. Gut. $3: 172$.

12. Nealon, T. F., Jr., and N. Ching. 1962. An extracorporeal device to lower blood ammonia levels in hepatic coma. Trans. Am. Soc. Artif. Intern. Organs. 8: 226.

13. Chaudry, N. C., J. S. Juggi, and I. D. Singh. 1962. Removal of excessive ammonium from artificial serum by passage over cation-exchange resins. Lancet. 1: 1262.

14. Juggi, J. S. 1971. Haemoperfusion through cation exchange columns in the treatment of ammonium intoxication in dogs. Proc. Soc. Exp. Biol. Med. 137: 39.

15. Juggi, J. S. 1973. Extracorporeal cation-exchange circuits in the treatment of hyperammonaemia of hepatic failure. Med. J. Aust. 1: 926.

16. Rosenbaum, J. L., M. S. Kramer, R. Raja, and C. Boreyko. 1971. Resin hemoperfusion: A new treatment for acute drug intoxication. N. Engl. J. Med. 284: 874.

17. Rosenbaum, J. L., S. Winsten, M. S. Kramer, J. Moros, and R. Raja. 1970. Resin hemoperfusion in the treatment of drug intoxication. Trans. Am. Soc. Artif. Intern. Organs. 16: 134.

18. Cohn, H. E., A. J. Weiss, J. E. Clark, and T. F. Nealon, Jr. 1960. An ion-exchange resin artificial kidney. Surg. Forum. 11: 15.

19. Rosenbaum, J. L., G. Onesti, and C. Heider. 1962. The rapid removal of cations from dogs with an ionexchange column. J. Am. Med. Assoc. Second multidiscipline research forum. 180: 762 .

20. Yatzidis, H. 1964. A convenient haemoperfusion microapparatus over charcoal for the treatment of endogenous and exogenous intoxications: its use as an effective artificial kidney. Proc. Eur. Dialysis Transplant Assoc. $1: 83$.

21. Dunea, G., and W. J. Kolff. 1965. Clinical experience with the Yatzidis charcoal artificial kidney. Trans. Am. Soc. Artif. Intern. Organs. 11: 178.

22. Chang, T. M. S. 1964. Semipermeable microcapsules. Science (Wash. D. C.). 146: 524.

23. Chang, T. M. S., F. C. MacIntosh, and S. G. Mason. 1966. Semipermeable aqueous microcapsules. I. Preparation and properties. Can. J. Physiol. Pharmacol. 44: 115.

24. Chang, T. M. S. 1969. Removal of endogenous and exogenous toxins by a microencapsulated adsorbent. Can. J. Physiol. Pharmacol. 47: 1043.

25. Chang, T. M. S., A. Gonda, J. H. Dirks, J. F. Coffey, and T. Lee-Burns. 1972. ACAC microcapsule artificial kidney for the long term and short term management of eleven patients with chronic renal failure. Trans. Am. Soc. Artif. Intern. Organs. 18: 465.

26. Decker, W. J., H. F. Combs, and D. G. Corby. 1968. Adsorption of drugs and poisons by activated charcoal. Toxicol. Appl. Pharmacol. $13: 454$.

27. Decker, W. J., H. F. Combs, J. J. Treuting, and R. J. Banez. 1971. Dialysis of drugs against activated charcoal. Toxicol. Appl. Pharmacol. 18: 573.

28. Yatzidis, H., D. Oreopoulos, D. Triantaphyllidis, S. Voudiclari, N. Tsaparas, C. Gavras, and A. Stavroulaki. 1965. Treatment of severe barbiturate poisoning. Lancet. 2: 216.

29. Hagstam, K. E., L. E. Larsson, and H. Thysell. 1966. Experimental studies on charcoal hemoperfusion in phenobarbital intoxication and uremia, including histopathologic findings. Acta Med. Scand. 180: 593. 
30. De Myttanaere, M. H., J. F. Maher, and G. E. Schreiner. 1967. Hemoperfusion through a charcoal column for glutethimide poisoning. Trans. Am. Soc. Artif. Intern. Organs. 13: 190.

31. Chang, T. M. S., J. F. Coffey, P. Barré, A. Gonda, J. H. Dirks, M. Levy, and C. Lister. 1973. Microcapsule artificial kidney: treatment of patients with acute drug intoxication. Can. Med. Assoc. J. 108: 429.

32. Willson, R. A., R. P. H. Thompson, J. Winch, and R. Williams. 1973. Rapid removal of paracetamol by haemoperfusion through coated charcoal. In-vivo and in-vitro studies in the pig. Lancet. 1: 77.
33. Barakat, T., and I. W. MacPhee. 1971. Bilirubin and alkaline phosphatase clearance from blood-plasma by perfusion through activated carbon. Br. J. Surg. 58: 355.

34. Chang, T. M. S. 1972. Hemoperfusion over microencapsulated adsorbent in a patient with hepatic coma. Lancet. 2 : 1371.

35. Schmid, R., I. Diamond, L. Hammaker, and C. B. Gunderson. 1965. Interaction of bilirubin with albumin. Nature. (Lond.). 206: 1041.

36. Scharschmidt, B. F., P. D. Berk, and J. G. Waggoner. 1973. Bilirubin (BR) kinetics in the normal rat. Clin. Res. $21: 523$. 